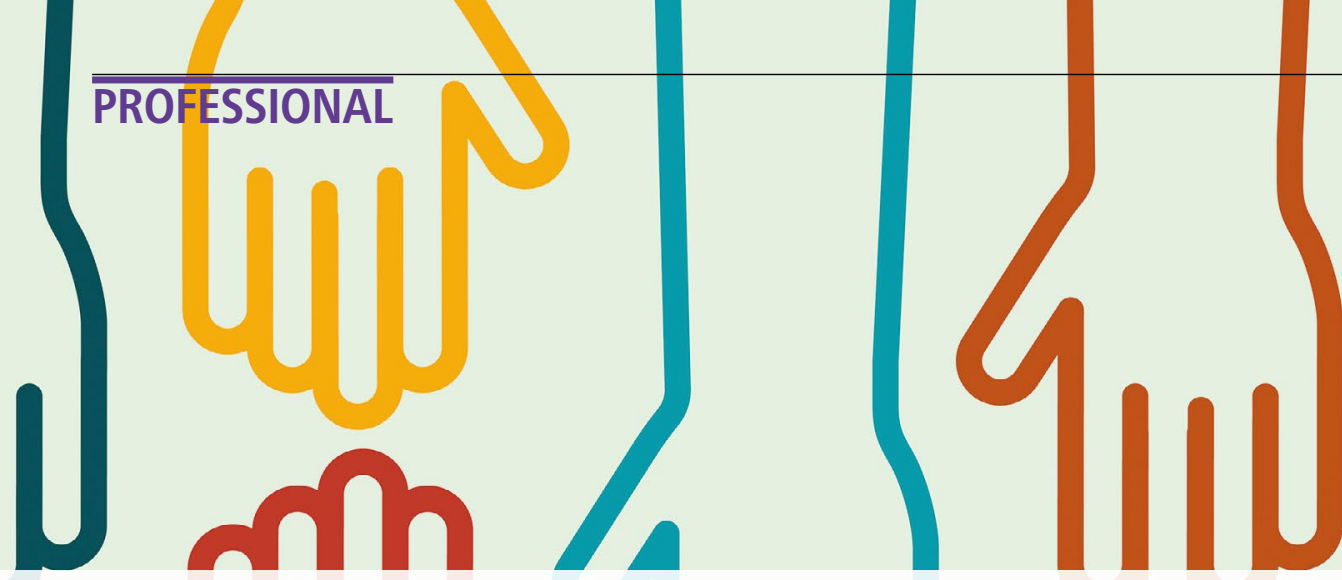

\title{
HOW YOU CAN GET INVOLVED IN COMMUNITY PROJECTS TO IMPROVE ACCESS TO DENTAL CARE AND MEET THE NEEDS OF YOUR LOCAL POPULATION
}

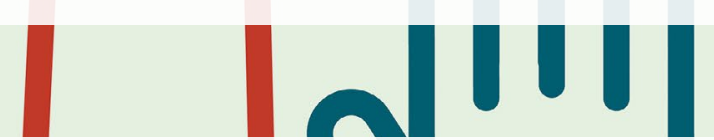

By Serena Dodhia, Academic Foundation Dentist, Central London Scheme

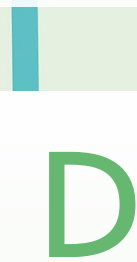

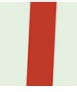

ental caries is one of the most common chronic diseases of childhood and can lead to a host of problems, including: pain, infection, time off school, reduced growth, delays to speech development and poor psycho-social wellbeing. ${ }^{1}$ Despite being largely preventable, the percentage of children with one or more decayed, missing or filled teeth in the London Borough of Brent is higher than the London average. ${ }^{2}$ In addition, child obesity rates in Brent have been higher than the national average since 2008.2 Many factors contribute to these statistics and I believe an essential way of tackling these important issues is widening access to dental care and reinforcing prevention to parents and children through community engagement projects.

We as dentists routinely reinforce and provide prevention to our paediatric patients in practice, including oral hygiene instruction, fluoride varnish application and diet advice as per Delivering Better Oral Health Guidelines. ${ }^{3}$ However, despite being free under the NHS, not all children have access to dental care. In addition, during the COVID-19 pandemic, it has been extremely difficult for children to access the dentist for either routine check-ups or emergency appointments. Local community initiatives are a valuable way for health care professionals including dentists, dental therapists and students to provide effective interventions, e.g. prevention to children and their parents. These initiatives can enable us to understand our patients better and be the important stepping stone for some patients in accessing dental care, especially after the pandemic, where habits, lifestyles and social circumstances have certainly changed.

In September last year I took part in the Oral Health Pop-up Bus in the Borough of Brent which invited children from nearby schools and nurseries to attend for free dental checks, fluoride varnish (22600ppm fluoride) application and oral health promotion. The dental checks identified high-risk children with caries and we provided advice on when the children should see their dentist next and how to register with local practices for those not registered with a dentist. If further attention was required, referrals were made to nearby community dentists who could deliver urgent care. For some children the pop-up bus was their first ever experience in a dental environment, highlighting the importance of community initiatives such as this in improving access to health care for, in my opinion, those who could benefit the most.

\section{Why take part in community} initiatives?

- Community engagement projects not only benefit the local population but also provide you with essential leadership opportunities as well as improving your communication and interpersonal skills. These important skills can help you deliver patient care to the highest standards in your clinical practice.

- Taking part in these projects during dental school can improve your confidence when treating patients and provide opportunities to practice your clinical skills outside of the dental hospital.

- You will get the opportunity to work with the wider dental team including dentists, dental therapists, dental nurses as well as key community figures such as teachers, the council, local NHS teams, pharmacies and GP practices.

- These initiatives also give you a better understanding of the health inequalities that are present in the community and the differing health needs of different sub groups in the local community. ${ }^{4}$

- In addition, these experiences can lead to exposure and interest into different career pathways that you may not have considered before, such as community dentistry or paediatric dentistry. 


\section{A guide on how to start a community outreach project}

Planning is key before starting a community project. Figure 1 illustrates the steps involved in designing a community outreach project. First identify a target group with health needs and intervention, for example: adults with learning disabilities and delivering oral hygiene instruction. Next liaise with existing organisations, your university and charities to organise how to deliver the intervention and if they can aid with access to oral health promotion materials, dental equipment and advertising the initiative in the local community. It is important to gain feedback from the local community after the project on their experiences as this can help inform further projects and lead to positive improvements to the project. Lastly, reflection on the project is essential to determine its effectiveness and the outcome to the local community as well as the impact the project has had on your experiences as a dental health professional.

\section{'For some children the pop-up bus was their first ever experience in a dental environment'}

\section{Tips on how to engage with local community initiatives}

There are many ways that you can get involved with community projects, such as the oral health pop-up bus, as a student and during foundation training. Here are my five tips to help you:

1. Become familiar with the local community environment around the university dental hospital or your dental practice as this can help you understand these patients better and communicate effectively with them.

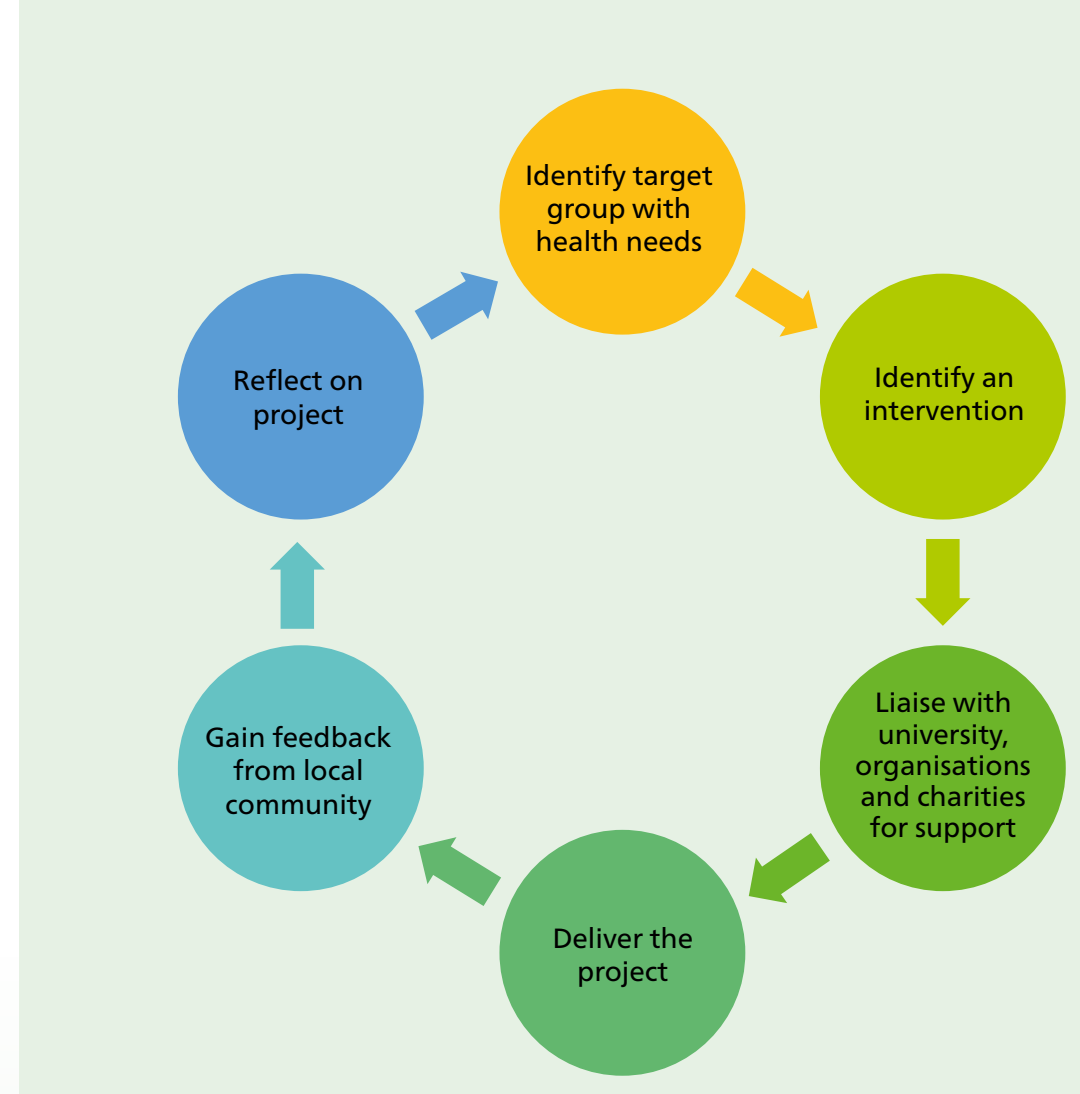

Fig. 1 Community outreach project design cycle

2. Connect with your university supervisors/ training programme director with your ideas and find out if they conduct any local initiatives that you can get involved with.

3. Look out for local projects that exist already in your local community and contact the organisers for more information on how to take part.

4. Practice communicating simple oral hygiene instructions and diet advice and contact local schools to visit and deliver this oral health prevention advice to with your peers.

5. If these opportunities are not available in your local area already then do not be afraid to start community projects alongside your peers. No matter how small, you will be making a difference.

I encourage all dentists, dental therapists and students to participate in community projects such as this to address health inequalities that exist and help meet the health needs of your local community. Investing your time in these valuable projects will undoubtedly benefit you as a clinician in the future by strengthening communication and leadership skills as well as clinical practical skills and can open the door to further opportunities and experiences.

\section{References}

1. Public Health England. Inequalities in Oral Health in England. 2021 Available at: https://assets.publishing. service.gov.uk/government/uploads/system/uploads/ attachment_data/file/970380/Inequalities_in_oral_ health_in_England.pdf (Accessed December 2021).

2. Brent Clinical Commissioning Group. People and Place. 2020. Available at: https://democracy.brent. gov.uk/documents/s94534/6a.\%20Appendix $\% 20$ 2\%20-\%20JSNA.pdf (Accessed December 2021).

3. Delivering Better Oral Health: An evidence based toolkit for prevention. GOV.UK. 2017.

4. Witton R and Paisi M. The benefits of an innovative community engagement model in dental undergraduate education, Educ Prim Care 2021; 1-5: doi: 10.1080/14739879.2021.1947160. Online ahead of print.

https://doi.org/10.1038/s41406-022-0290-2 